\title{
Bovine mastitis caused by Listeria monocytogenes: characteristics of natural and experimental infections
}

\author{
A. BOURRY*, B. POUTREL ${ }^{*} \ddagger$ and J. ROCOURT $\dagger$ \\ * Institut National de la Recherche Agronomique, Laboratoire de Pathologie Infectieuse et Immunologie, 37380 \\ Nouzilly and $\dagger$ Centre National pour la Lysotypie et le Typage Moléculaire de Listeria, Institut Pasteur, 75724 Paris, \\ Cedex 15, France
}

\begin{abstract}
Summary. Experimental mastitis induced with a single intramammary injection of Listeria monocytogenes was compared with two naturally occurring cases. Four strains of $L$. monocytogenes, two of serotype $1 / 2 \mathrm{a}$ and two of serotype $4 \mathrm{~b}$ were used for the experimental infections and two diametrically opposed quarters of four cows were inoculated with $300 \mathrm{cfu}$. Bacteriological examination and somatic cell counts of quarter foremilk samples were performed weekly for at least 6 months after challenge. All the inoculated quarters developed chronic subclinical mastitis with occasional clinical episodes. The results were similar to those observed in natural listeria mastitis. Four experimentally infected quarters were treated during lactation (gentamicin and cloxacillin) or at "drying-off" (cloxacillin), or at both times. Only one of four quarters was cured after treatment only at "drying-off". All experimental and naturally infected animals were slaughtered and bacteriological examination was performed on liver, spleen and supramammary, iliac and mesenteric lymph nodes. L. monocytogenes strains were isolated from the supramammary lymph nodes of two experimentally and two naturally infected cows and from an iliac lymph node from one of the naturally infected cows. The epidemiological data were supported by serotyping, lysotyping and DNA macro-restriction analysis. The experimental model of listeria mastitis mimics spontaneous cases and should be useful in further studies of listeria mastitis.
\end{abstract}

\section{Introduction}

Listeria monocytogenes is an important food-borne pathogen, and contaminated raw milk and milk products $^{1-3}$ have been involved in several outbreaks of listeriosis. ${ }^{4,5}$ Some reports have indicated that $L$. monocytogenes can survive pasteurisation. ${ }^{6,7}$ Although raw milk may be contaminated from environmental sources, ${ }^{8,9}$ several cases of bovine mastitis caused by $L$. monocytogenes have been reported. ${ }^{10-12}$

In an attempt to explain the low incidence of mastitis caused by $L$. monocytogenes, Fedio et al. ${ }^{13}$ suggested that either the techniques used to detect the presence of the organism in milk were unreliable or that the organism was not invasive for the bovine udder. However, mastitis has been induced experimentally after several repeated intramammary injections of large numbers of $L$. monocytogenes. ${ }^{14}$ The route by

Received 22 Nov. 1994; accepted 18 Jan. 1995.

¥Correspondence should be sent to Dr B. Poutrel. which $L$. monocytogenes infects the udder naturally remains unknown. The udder could be infected by penetration of the teat or by localisation after systemic infection. ${ }^{15}$ Regardless of the route, contamination of raw milk with $L$. monocytogenes is a public health risk. Antibiotics are not effective in treating intramammary infection by $L$. monocytogenes and infected animals have to be culled from the herd. ${ }^{13}$

Because of the low frequency of naturally occurring cases of mastitis caused by $L$. monocytogenes, an experimental model of udder infection is needed, both to understand the characteristics of infection and to evaluate the risk of contamination of raw milk. In this study, an experimental model for inducing bovine mastitis was developed that used a single inoculation with a few bacteria of different strains of $L$. monocytogenes. The results concerning contamination of milk after experimental intramammary infection of cows by $L$. monocytogenes throughout lactation, as well as infection of lymph nodes and organs, are presented and compared with naturally occurring cases of mastitis. 


\section{Materials and methods}

Cows

Two cows with naturally occurring listeria mastitis were detected in separate herds. Infections appeared in the first month after calving. Cow 204 was infected with $L$. monocytogenes serotype 4 b strain D7U22 in its left hind ( $\mathrm{LH})$ quarter and cow 2187 with serotype $1 / 2$ a strain D7P09 in its right hind (RH) quarter. Both cows were kept for 2 weeks at INRA, Nouzilly, France, before slaughtering. For the experimental infections, four lactating Holstein cows $(020,026,808$ and 905), free of intramammary infection, were selected from our experimental herd. Two cows ( 026 and 905) were 2 months pregnant. The cows were isolated from the herd and milked with two milking units which were washed and disinfected between each animal. The animals were slaughtered 30 weeks (808), 33 weeks $(026$ and 905$)$ or 38 weeks $(020)$ after intramammary inoculation of $L$. monocytogenes.

\section{Bacteria and challenge}

Four strains of L. monocytogenes, two of serotype $4 \mathrm{~b}$ and two of serotype $1 / 2 \mathrm{a}$, were used for experimental intramammary inoculation. The serotypes and main characteristics of the strains used are summarised in table I. Strain D7R05 was provided by Professor J. Bille (Centre Hospitalier Universitaire Vaudois, Lausanne, Switzerland). Challenge inocula were prepared by growing bacteria in $10 \mathrm{ml}$ of Brain Heart Infusion Broth (BHI; Difco) for $18 \mathrm{~h}$ at $37^{\circ} \mathrm{C} ; 2 \mathrm{ml}$ of this culture were inoculated into $10 \mathrm{ml}$ of $\mathrm{BHI}$ and cultured for $6 \mathrm{~h}$ at $37^{\circ} \mathrm{C}$. Dilutions in physiological buffer $\left(\mathrm{NaCl} 0.8 \% \mathrm{w} / \mathrm{v}, \mathrm{NaHPO}_{4} 0.01 \mathrm{M}\right.$ ) were then made to obtain a concentration of $1.5 \times 10^{3} \mathrm{cfu} / \mathrm{ml}$ adjusted by measuring optical density. The bacterial suspension $(0.2 \mathrm{ml}, 300 \mathrm{cfu})$ was injected just after milking into the teat duct of two diametrically opposed quarters. ${ }^{16}$

\section{Bacteriological examination of milk samples}

Quarter foremilk samples were collected aseptically just before milking, daily from the naturally infected cows and weekly from the experimentally infected cows. For the latter, $1 \mathrm{ml}$ of milk was sonicated for $30 \mathrm{~s}$ at a power setting of $8 \mathrm{~W}$ (Sonics and Materials, Danbury, Connecticut, USA), to release intracellular
L. monocytogenes and to disperse bacterial aggregates. Either non-sonicated milk or sonicated milk $(0.1 \mathrm{ml})$ was plated directly on sheep blood agar and incubated for $18-24 \mathrm{~h}$ at $37^{\circ} \mathrm{C}$ for bacterial examination. The milk samples were not diluted; consequently $2500 \mathrm{cfu} / \mathrm{ml}$ was the upper limit considered for counting bacteria.

\section{Milk somatic cell counts (SCC)}

The milk SCC were determined with an electronic cell counter (Coulter model ZM ; Coultronics, Margency, France) according to the method of the International Dairy Federation. ${ }^{17}$

\section{Post-mortem examination}

Samples (4-53 mg) of liver, spleen, supramammary and iliac lymph nodes (right and left) and mesenteric lymph nodes were taken aseptically from all cows immediately after slaughter. Samples were frozen at $-20^{\circ} \mathrm{C}$ within $1 \mathrm{~h}$ of collection. Organ and lymph node samples from spontaneously infected cows were allowed to thaw at room temperature and then homogenised in 3 volumes ( $3 \mathrm{ml} / \mathrm{g}$ of sample) of trypticase soy broth supplemented with yeast extract (TSB-YE). This suspension was then diluted in $100 \mathrm{ml}$ of TSB-YE and TSB-YE supplemented with inhibitors (acriflavin 0.002\% w/v, nalidixic acid $0.004 \% \mathrm{w} / \mathrm{v}$, cycloheximide $0.006 \% \mathrm{w} / \mathrm{v}$ ) and incubated for 1 week at $37^{\circ} \mathrm{C}$ or 2 months at $4^{\circ} \mathrm{C}$, respectively. At the end of the incubation period, $0 \cdot 2-\mathrm{ml}$ volumes were plated on PALCAM agar ${ }^{18}$ (Biokar Diagnostics, Beauvais, France) and cultures were examined after $18 \mathrm{~h}$ at $37^{\circ} \mathrm{C}$. For the experimentally infected cows, tissue samples were treated according to the protocol recommended by the French Department of Agriculture and Fishing $^{19}$ for the detection of $L$. monocytogenes in milk products. In brief, after thawing at room temperature, samples were homogenised with Fraser $1 / 2$ broth and one volume was added to 9 volumes of Fraser $1 / 2$ broth. After $18-24 \mathrm{~h}$ at $37^{\circ} \mathrm{C}$ (primary enrichment) $0.1 \mathrm{ml}$ of the culture was added to $10 \mathrm{ml}$ of Fraser broth and incubated for $24-48 \mathrm{~h}$ at $37^{\circ} \mathrm{C}$ (secondary enrichment). PALCAM agar plates were used for the isolation of bacteria. This was repeated at $48 \mathrm{~h}$ if no growth occurred after incubation for $24 \mathrm{~h}$ in Fraser broth.

Table I. Quarters infected and characteristics of L. monocytogenes strains used for experimental mastitis

\begin{tabular}{clllcc}
\hline Cow & Infected quarters & Strain no. & Origin & Serovar & Phagovar \\
\hline 020 & RF, LH & INRA D7U22 & Bovine mastitis & $4 \mathrm{~b}$ & $3552,3274,108,340,312$ \\
026 & RF, LH & CNL 895789 & Bulk milk & $1 / 2 \mathrm{a}$ & $1967,4477,12029,10,43$ \\
808 & RH, LF & INRA D7R05 & Human & $4 \mathrm{~b}$ & $2389,3552,47,52,108,340,312$ \\
905 & RH, LF & INRA D7P09 & Bovine mastitis & $1 / 2 \mathrm{a}$ & $1967,1652,10,21,43,46$
\end{tabular}




\section{Antibiotic therapy and antibiotic susceptibility of isolates}

At 18 and 20 weeks after experimental infection, all infected quarters of cows 808 and 905 were treated during lactation with two intramammary injections of a combination of gentamicin $(50 \mathrm{mg})$ and cloxacillin (200 mg) (Gentamam; Schering-Plough Santé Animale, Segré, France). The efficiency of treatment was determined weekly by microbiological examination of milk samples for 3-4 weeks after injection of the antibiotics. At "drying-off", each quarter of cows 026 and 905 was treated with a single intramammary injection of benzathine-cloxacillin (756 mg; Orbenor, Smithkline Beecham Pharmaceuticals, Brentford) according to the manufacturer's recommendations.

The susceptibility of $L$. monocytogenes strains isolated from tissues and milk samples to gentamicin and cloxacillin was investigated before and after treatments. Antibiograms were determined by the conventional Kirby-Bauer disk diffusion test on MuellerHinton agar incubated for $24 \mathrm{~h}$ at $35^{\circ} \mathrm{C}$. Diameters of zones of growth inhibition were measured and antibiograms were interpreted according to the manufacturer's recommendations (Diagnostics Pasteur, Marnes-la-Coquette, France).

\section{Characterisation of L. monocytogenes isolates}

Twenty-four strains of $L$. monocytogenes were isolated from milk and tissue samples from experimentally infected cows. Serotyping and lysotyping were performed for strains isolated from the infected quarters of each cow, the week after the challenge and 17-21 weeks later, from the newly infected quarters of cow 808 and from infected quarters of cow 905 after antibiotic treatment. The strains isolated from the lymph nodes of cows 808 and 905 , and from quarter milk samples of cows 026 and 905 after calving were also characterised.

Serogroups and phagovars were determined with unabsorbed sera prepared according to the reference method $^{20}$ and with the international set of bacteriophages ${ }^{21}$ respectively. These strains were further characterised by DNA macro-restriction analysis: DNA was digested by ApaI or SmaI and the fragments generated were separated by pulsed-field gel electrophoresis (PFGE) as described previously. ${ }^{22,23}$

\section{Results}

\section{Clinical observations}

No clinical episode was recorded for cows 204 and 2187 with natural intramammary infection during the period of observation. The four experimentally infected cows developed mastitis in all the quarters inoculated with the different strains of L. monocytogenes. Infections were usually subclinical and the udders appeared normal, although milk clots were
Table II. $L$. monocytogenes numbers in non-sonicated quarter foremilk samples from naturally (204 and 2187) and experimentally $(020,026,808$ and 905$)$ infected cows

\begin{tabular}{rlcc}
\hline $\begin{array}{c}\text { Cow } \\
\text { no. }\end{array}$ & $\begin{array}{c}\text { Infected } \\
\text { quarter }\end{array}$ & $\begin{array}{c}\text { Number of } \\
\text { samples }\end{array}$ & $\begin{array}{c}\text { Range of } \\
\text { Lonocytogenes } \\
\text { counts } \\
\text { (cfu/ml) }\end{array}$ \\
\hline 204 & LH & 9 & $720-2000$ \\
2187 & RH & 9 & $1620->2500$ \\
020 & RF & 25 & $0-2160$ \\
& LH & 23 & $15->2500$ \\
026 & RF & 17 & $35->2500$ \\
& LH & 17 & $10-2420$ \\
808 & RH & 20 & $125->2500$ \\
& LF & 9 & $420->2500$ \\
905 & RH & 17 & $120->2500$ \\
& LF & 17 & \\
\hline
\end{tabular}

sometimes detected in samples from cows 808 and 905 . Cows 026 and 905 , which were pregnant, gave birth to healthy calves. The LH quarter of cow 026 and the RH and LF quarter of cow 905 showed persistent infection during the next lactation. The RF quarter of cow 905 developed a naturally occurring case of listeria mastitis 5 days after calving. Cow 905 became infected by Streptococcus uberis in its RF quarter 3 weeks after challenge. This infection was not treated with antibiotics and persisted throughout lactation.

\section{Bacteriological examination of milk}

The numbers of L. monocytogenes, in non-sonicated quarter foremilk samples, ranged from 720 to $>2500 \mathrm{cfu} / \mathrm{ml}$ for the naturally infected cows and from none to $>2500 \mathrm{cfu} / \mathrm{ml}$ for the experimentally infected cows (table II). One week after experimental challenge, non-sonicated milk samples from all cows were positive for L. monocytogenes. L. monocytogenes was not isolated from four RF quarter milk samples from cow 020 , but was consistently isolated from all quarters milk samples from the other cows. Sonication of the milk increased the number of cfu; $>2500 \mathrm{cfu} / \mathrm{ml}$ were isolated in $65(46 \%)$ of 141 samples of sonicated milk compared with $40(27 \%)$ of 149 non-sonicated samples. L. monocytogenes was not isolated from four samples of non-sonicated milk from cow 020, whereas the organism was isolated from three samples after sonication (table III).

\section{Milk somatic cell counts}

The mean milk SCC of samples from the naturally infected quarters of cows 204 and 2187 were $>10^{6}$ cells $/ \mathrm{ml}$. During the course of infection 1-5-fold variation in SCC was observed among the milk samples from each infected quarter (table IV). Similar results were observed for the RF and $\mathrm{LH}$ quarters for cow 808 , in which natural infection with L. monocytogenes occurred during the experiment.

For experimentally infected quarters, the mean SCC were also $>10^{6}$ cells $/ \mathrm{ml}$ except in the RF quarter of 
Table III. Effect of sonication on number of cfu isolated by direct plating of quarter foremilk samples from cows infected experimentally with $L$. monocytogenes

\begin{tabular}{lcccccc}
\hline \multirow{2}{*}{$\begin{array}{c}\text { Treatment } \\
\text { of } \\
\text { milk }\end{array}$} & \multicolumn{4}{c}{ Number of samples with counts of } & \multirow{2}{*}{$\begin{array}{c}\text { Total } \\
\text { number } \\
\text { of samples }\end{array}$} \\
\cline { 2 - 5 } & $0 \mathrm{cfu}$ & $1-125 \mathrm{cfu}$ & $126-250 \mathrm{cfu}$ & $>250 \mathrm{cfu}$ & 149 \\
\hline $\begin{array}{l}\text { Non-sonicated } \\
\text { Sonicated }\end{array}$ & 4 & 91 & 14 & 40 & 141 \\
\hline
\end{tabular}

Table IV. Somatic cell counts (SSC) of quarter foremilk samples from cows with natural (204 and 2187) and experimental $(020,026,808$ and 905) infections by L. monocytogenes

\begin{tabular}{ccccc}
\hline & \multicolumn{5}{c}{ Geometric mean (range) of SCC $\left(\times 10^{3} / \mathrm{ml}\right)$} \\
\cline { 2 - 5 } Cow no. & RF & RH & LF & LH \\
\hline \multirow{2}{*}{204} & 152 & 178 & 165 & $1427^{*}$ \\
& $(115-246)$ & $(114-257)$ & $(95-249)$ & $(665-3689)$ \\
2187 & 315 & $6697^{*}$ & 183 & 179 \\
& $(161-568)$ & $(4090-15279)$ & $(111-266)$ & $(137-262)$ \\
020 & $897^{*}$ & 220 & 203 & $2176^{*}$ \\
& $(303-3380)$ & $(124-523)$ & $(81-415)$ & $(884-6039)$ \\
026 & $1039^{*}$ & 266 & 333 & $1090^{*}$ \\
& $(534-2174)$ & $(119-2780)$ & $(162-562)$ & $(542-2419)$ \\
808 & $2749^{*}+$ & $1687^{*}+$ & $8419^{*}$ & $2720^{*} \dagger$ \\
& $(1004-6812)$ & $(984-3379)$ & $(2544-32897)$ & $(1845-5803)$ \\
905 & $3526 \$$ & $5423^{*}$ & $3431^{*}$ & 378 \\
& $(317-10347)$ & $(2184-13511)$ & $(1129-9096)$ & $(201-811)$ \\
\hline
\end{tabular}

*Quarters infected by $L$. monocytogenes.

† Means were calculated from values recorded after spontaneous infection.

${ }_{+}^{+}$Mean was calculated from values recorded before spontaneous recovery.

$\$$ Natural infection with $S$. uberis.

cow 020. One to 13-fold variations in SCC were observed in the individual milk samples. The high milk SCC in the RF quarter of cow 905 was due to infection by $S$. uberis.

\section{Antibiotic therapy}

Intramammary antibiotic therapy during lactation of cows 808 and 905 with gentamicin-cloxacillin was ineffective. All quarters inoculated with antibiotics shed $>2500$ L. monocltogenes $/ \mathrm{ml}$ of milk until "drying-off" 3-4 weeks after treatment (data not shown). After calving, cow 026 excreted L. monocytogenes from one experimentally infected quarter and cow 905 from two experimentally infected quarters, despite treatment with benzathine-cloxacillin at "drying-off". All strains isolated after treatment during lactation or at " drying-off" were susceptible to the corresponding antibiotic.

\section{Bacteriological examination of organs and lymph nodes}

L. monocytogenes was not isolated from organ samples of naturally infected cows by direct plating on sheep blood agar or on PALCAM. The left supramammary lymph node of cow 204, and the left iliac and the right supramammary lymph nodes of cow
Table V. Presence of L. monocytogenes in various organs and lymphatic nodes (LN) from cows with spontaneous ( 204 and $2187)$ or induced $(020,026,808$ and 905$)$ mastitis

\begin{tabular}{llllllll}
\hline \multirow{2}{*}{ Sample } & \multicolumn{9}{c}{ Presence of } & \multicolumn{1}{c}{ monocytogenes in cow no. } \\
\cline { 2 - 7 } & 204 & 2187 & 020 & 026 & 808 & 905 \\
\hline Liver & - & - & - & - & - & - \\
Spleen & - & - & - & - & - & - \\
Right supramammary & - & + & - & - & + & + \\
LN & & & & & & \\
Left supramammary & + & - & - & - & - & + \\
LN & & & & & & \\
Right iliac LN & - & - & - & - & - & - \\
Left iliac LN & - & + & - & - & - & - \\
Mesenteric LN & - & - & - & - & - & - \\
\hline
\end{tabular}

+ . Presence of L.monocytogenes;,- L. monocytogenes not isolated.

2187, were positive for L. monocytogenes after incubation for 2 months at $4^{\circ} \mathrm{C}$ in TSB-YE (table V).

L. monocytogenes was not isolated by direct plating of homogenised samples from experimental infections on to sheep blood agar and PALCAM. After the first phase of enrichment, L. monocytogenes colonies were isolated in pure culture from the right supramammary lymph node of cow 808, and from the two supramammary lymph nodes of cow 905 (table V). None was found in tissue samples of cows 020 and 026 , even after culture for $48 \mathrm{~h}$ in Fraser broth. 
a

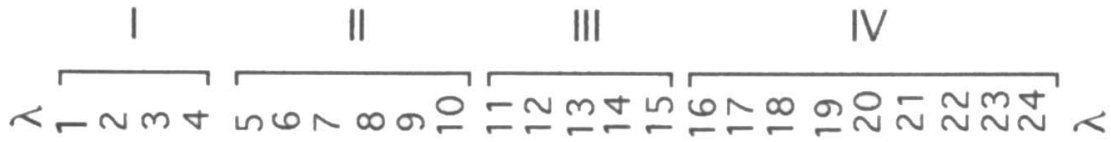


Figure. PFGE resolving (a) ApaI and (b) SmaI restriction fragments from L. monocytogenes strains isolated from different milk samples and lymph nodes (LN) of experimentally infected cows. Profile I (cow 020): lanes 1, 2 and 3, 4, RF and LH quarters respectively, 1st and 25 th week post-inoculation (Pi). Profile II (cow 808): lanes 5, 6, RH quarter 1st and 18th week Pi; 7, LH quarter 1st week Pi;8 and 9, RF and LH quarters (spontaneous infections); 10, right supramammary LN. Profile III (cow 026): lanes 11, 12 and 13, 14, RF and LH quarters respectively, 1st and 17 th week Pi; 15, LH quarter 6th day after calving. Profile IV (cow 905): lanes 16, 17 and 18, 19, RH and LF quarters respectively, 1st week Pi and after treatment during lactation; 20, 21 and 22, RH, LF and RF quarters respectively, after calving; 23 and 24 : right and left supramammary $\mathrm{LN} ; \lambda$, lambda DNA-concatamers. 


\section{Characterisation of L. monocytogenes isolates}

The 24 strains were divided in four different genomic varieties by PFGE. according to their restriction pattern with ApaI or SmaI. Restriction profiles are shown in the figure. Each genomic variety was constituted by the strains isolated from the same cow. After lysotyping and serotyping, the 24 strains were also divided into four types. All the strains isolated from a given cow had identical serotype and lysotype, corresponding to those of the strain used for the experimental infection. Moreover, the strains isolated from the spontaneous infections that appeared in RF and L.H quarters of cow 808 during lactation and in the RF quarter of cow 905 after calving were similar to the strain used for inoculation in the other quarters. $L$. monocytogenes strains isolated from the lymph nodes of cows 808 and 905 were also identical to the strains used for challenge.

\section{Discussion}

The route of infection for naturally occurring cases of listeria mastitis still remains controversial. However, it appears likely that a few bacteria penetrating the teat canal can produce an infection. If the mammary quarter is the original site of infection of $L$. monocytogenes. the stages in the infection process would probably be the same as those proposed by Bramley and Dodd. ${ }^{24}$ The bacteria have to contaminate the teat end before penetration into the quarter. In the present study, infection was induced with a single inoculation of $300 \mathrm{cfu}$, which may be close to the infecting dose in naturally occurring listeria mastitis. All inoculated quarters were infected regardless of the serotype or the origin of the strains. Both the strain isolated from raw milk and the human strain were able to induce mastitis, and no relationship could be found between the serotype of the infecting strain and the severity of the infection. The features of these experimental infections were the same as those observed in the two naturally occurring cases. The mean SSC in milk samples from all $L$. monocytogenes infected quarters often exceeded $10^{6}$ cells, with great variation among milk samples from the cows throughout the course of the infection. Although clinical episodes were rare. spontaneous and experimental listeria mastitis can be defined mainly as subclinical mastitis comparable to most Staphylococcus aureus intramammary infection. ${ }^{25}$ According to the terminology of Griffin et $a l . .^{26}$ pathogens involved in udder infections can be separated into minor and major pathogens. Minor pathogens (unlike major pathogens), cause small inflammatory reactions of usually $<10^{6}$ cells $/ \mathrm{ml}$ of milk. Taking into account the severity of inflammation measured by SCC. L. monocytogenes should be considered as a major mastitis pathogen.

With the exception of the LF quarter of cow $808, L$. monocytogenes was shed continuously from all the experimental infected quarters as observed for natural cases. Similar results have been reported by Bryner $e t$ $a l{ }^{14}$ who also induced chronic listeria mastitis after experimental challenge. However, in their experimental listeria mastitis model, as well as other models described in published reports, ${ }^{7}$ infections were induced with repeated intramammary inoculations (2-9 times) of large numbers $\left(10^{3}-10^{7} \mathrm{cfu}\right)$ of $L$. monocytogenes and with additional injections into the supramammary lymph nodes. Under these conditions, the bacteria were isolated from other organs. ${ }^{14,27}$ Vishinsky et al. ${ }^{15}$ have also isolated L. monocytogenes from different organs of a cow with a naturally occurring case of listeria mastitis. The authors were not able to determine the original site of the infection.

Because outbreaks of listeriosis in man have been associated with consumption of contaminated food, the oral route is presently recognised as the route of infection of L. monocytogenes and the intestinal tissues as the initial site of invasion. ${ }^{28}$ When goats were infected orally with $6 \times 10^{9} \mathrm{cfu}$ of $L$. monocytogenes, organisms were isolated from their milk and faeces. ${ }^{29}$ A similar inoculum $\left(10^{8}-10^{9} \mathrm{cfu}\right)$ administered by the same route in mice infected spleen and draining lymph nodes. ${ }^{30}$ More recently, Bracegirdle et al.$^{31}$ compared aerosol and intragastric routes of infection in mice with approximately the same number of Listeria spp. All virulent strains of $L$. monocytogenes infected the animals and organisms were recovered from the liver and spleen. In the present study, the comparison of organs and lymph nodes from the two naturally occurring cases of listeria mastitis with those from two experimentally infected cows ( 808 and 905$)$ that were infected for $>7$ months, did not differ. Listeria were found in the supramammary node of four cows and in an iliac node of a spontaneously infected cow (2187). Listeria were never recovered from the liver or spleen, which usually becomes infected when high doses of Listeria are administered by the intramammary, the intragastric or the aerosol routes. ${ }^{27,30.31}$ In this study, L. monocytogenes never spread to other organs even 7 months after experimental or 2 weeks after natural infections. The draining lymph nodes of the udder apparently performed their protective role and prevented generalised infection. These results differ from those of Vishinsky et al..$^{15}$ who proposed that the spread of L. monocytogenes to other organs was the result of stress-induced bacteraemia after udder infection.

Despite the susceptibility of the strains to gentamicin, treatment with gentamicin-cloxacillin during lactation was not effective and cows 808 and 905 shed listeria continuously. Gentamicin was chosen because of its success in treating $L$. monocytogenes infection in man (A. Audurier, personal communication) and because gentamicin can kill intracellular $L$. monocytogenes in vitro. ${ }^{32}$ The results of this study are in agreement with other reports on the ineffectiveness of other antibiotics such as leocillin-dihydrostreptomycin, ${ }^{10}$ erythromycin-cephapirin, ${ }^{13}$ ampicillin-cephalothin and penicillin G-streptomycin ${ }^{15}$ in the treatment 
of listeria mastitis. In the present study, administration of benzathine-cloxacillin at "drying-off" was also ineffective in eliminating infection by listeria. The failure of treatment was not related to resistance of $L$. monocytogenes to the antibiotics as demonstrated by antibiograms with strains isolated after antibiotic treatment.

Serotyping, lysotyping and DNA macro-restriction analysis indicated that all the isolates from the same cow were identical and confirmed the persistence of the infection throughout the experiment. These results also confirmed the ineffectiveness of antibiotic treatment either during lactation or at "drying-off" since the strains used for the challenge were recovered throughout the experiment from cow 905 and in the next lactation in cows 026 and 905. Moreover, the strains isolated from the RF and LH quarters of cow 808 and from the RF quarter of cow 905 after calving were identical to the strains used for the experimental infection. These results indicated that these spontaneous infections were probably due to a crossinfection between the quarters of the cow during machine milking. ${ }^{33}$ Contamination of the supramammary or iliac lymph nodes by the same strains as those isolated in the udder was consistent with the possibility of the intramammary route of infection since listeria had not been detected in other organs.

In comparison with results obtained after sonication of milk samples, direct plating underestimated the level of counts of L. monocytogenes, so that there was a risk of false negative diagnosis of intramammary infection. However, because milk samples can be contaminated by pathogens from external sources, ${ }^{8,9}$ no reliable diagnosis is possible without careful aseptic sampling. ${ }^{34}$ Consequently, a risk of false positive diagnosis possibly exists when enrichment and selective media are used. Direct plating on agar base medium allows the evaluation of the sampling and we recommend this procedure in association with preliminary sonication of the milk samples for the

\section{References}

1. Dominguez-Rodriguez L, Fernandez-Garayzabal JF, VazquezBoland JA, Rodriguez-Ferri E, Suarez-Fernandez G. Isolation de micro-organismes du genre Listeria à partir de lait cru destiné à la consommation humaine. Can $J$ Microbiol 1985; 31 : 938-941.

2. Griffiths MW. Listeria monocytogenes: its importance in the dairy industry. J Sci Food Agric 1989; 47: 133-158.

3. Eilertz I, Danielsson-Tham ML, Hammarberg $\mathrm{KE}$ et al. Isolation of Listeria monocytogenes from goat cheese associated with a case of listeriosis in goat. Acta Vet Scand $1993 ; 34$ : 145-149.

4. Fleming DW, Cochi SL, MacDonald KL et al. Pasteurized milk as a vehicle of infection in an outbreak of listeriosis. $N$ Engl $J$ Med 1985; 312: 404-407.

5. Linnan MJ, Mascola L, Lou XD et al. Epidemic listeriosis associated with Mexican-style cheese. $N$ Engl J Med 1988; 319: $823-828$.

6. Fernandez-Garayzabal JF, Dominguez-Rodriguez L, VazquezBoland JA, Blanco-Cancelo JL, Suarez-Fernandez G. Listeria monocytogenes dans le lait pasteurisé. Can J Microbiol 1986; 32: 149-150.

7. Doyle MP, Glass KA, Berry JT, Garcia GA, Pollard DJ, Schultz RD. Survival of Listeria monocytogenes in milk diagnosis of mastitis caused by $L$. monocytogenes. Under the conditions of sonication used, somatic cells of milk samples were disrupted as determined by microscopic examination, and L. monocytogenes was not killed (data not shown). De Chastellier and Berche $^{35}$ have demonstrated simultaneous killing and survival of L. monocytogenes in macrophages. About $43 \%$ of the phagocytic cells in milk from quarters infected by Listeria were infected with $1.5-9 \cdot 2 \mathrm{~L}$. monocytogenes/phagocyte. ${ }^{7,36}$ These results could explain the persistence of infection by listeria and the scarcity of recovery, since antibiotics used in intramammary treatments are likely to be less efficient against intracellular L. monocytogenes.

Although listeria mastitis is rare, ${ }^{13}$ it poses a serious health risk, particularly when dairy industries use raw milk. The risk is due to both the persistence of infection as reported here and the level of milk contamination. On one occasion 60000 L. monocytogenes $\mathrm{cfu} / \mathrm{ml}$ of milk from an infected quarter were found (data not shown). Supposing, for example, in a herd of 50 cows each had a similar milk yield, the level of contamination of bulk milk would be in the order of $300 \mathrm{~L}$. monocytogenes $/ \mathrm{ml}$. Consequently, in order to prevent contamination of bulk milk, early detection of cows with listeria mastitis is required. This experimental infection model closely resembled naturally occurring cases, and should, therefore, be of value in the development of methods that are simpler and cheaper than bacteriological approaches for diagnosis of infection by $L$. monocytogenes and evaluation of treatments.

We are grateful to R. Boivin, B. Catimel, T. Cochard, J. Cognié, J. Dufrenoy and the staff of experimental facilities for their technical assistance. We thank M. J. Paape, P. Rainard and P. Sarradin for review of the manuscript. We are also grateful to J. L. Menard and M. Saana (Institut de l'Elevage, Paris) for the selection of naturally infected cows in farms and A. Audurier (Faculté de Médecine, Tours) for the serotyping and lysotyping of strains from the spontaneous infection. This work was partially supported by a grant from the Ministère de l'Enseignement Supérieur et de la Recherche and Vetoquinol Biotechnologie (Lure, France).

during high-temperature, short-time pasteurization. Appl Environ Microbiol 1987; 53: 1433-1438.

8. Husu JR, Seppänen JT, Sivelä SK, Rauramaa AL. Contamination of raw milk by Listeria monocytogenes on dairy farms. $J$ Vet Med B 1990; 37: 268-275.

9. Sanaa M, Poutrel B, Menard JL, Serieys F. Risk factors associated with contamination of raw milk by Listeria monocytogenes in dairy farms. $J$ Dairy Sci 1993; 76: 2891-2898.

10. Jensen J, Larsen HE. Listeria monocytogenes som ärsag til 3 tilfaelde af mastitis hos kvaeg. Nord Vet Med 1973; 25: 322-329.

11. Gitter M, Bradley M, Blampied PH. Listeria monocytogenes infection in bovine mastitis. Vet Rec 1980; 25: 390-393.

12. Sharp MW. Bovine mastitis and Listeria monocytogenes. Vet Rec 1989; 125: 512-513.

13. Fedio WM, Schoonderwoerd M, Shute RH, Jackson H. A case of bovine mastitis caused by Listeria monocytogenes. Can Vet $J$ 1990; 31: 773-775.

14. Bryner J, Wesley I, van der Maaten M. Research on listeriosis in milk cows with intramammary inoculation of Listeria monocytogenes. Acta Microbiol Hung 1989; 36: 137-140.

15. Vishinsky Y, Grinberg A, Ozery R. Listeria monocytogenes udder infection and carcase contamination. Vet Rec 1993; 133: 484 . 
16. Postle DS, Roguinsky M. Poutrel B. Induced staphylococcal infections in the bovine mammary gland. Am $J$ let Res 1978: 39: 29 35 .

17. International Dairy Federation. Milk enumeration of somatic cells. 1994: A-Doc 170.

18. van Netten P. Perales I, van de Mossdijk A. Curtis GDW. Mossel DAA. Liquid and solid selective differential media for the detection and enumeration of L. monocrtogenes and other Listeria spp. Int J Food Microbiol 1989: 8: 299-316.

19. Journal Officiel de la République Française. Recherche de Listeria monocltogenes. 17 mai 1994: 7245-7248.

20. Seeliger HPR. Höhne K. Serotyping of Listeria monocytogenes and related species. In : Bergan T. Norris J (eds) Methods in microbiology, vol 13. New York. Academic Press. 1979: $31-49$.

21. Rocourt J, Audurier A, Courtieu AL et al. A multi-centre study on the phage typing of Listeria monocytogenes. Zentralbl Bakteriol Mikrobiol Hiy A 1985: 259: 489-497.

22. Buchrieser C. Brosch R. Rocourt J. Use of pulsed field gel electrophoresis to compare large DNA-restriction fragments on Listeria monoryogenes strains belonging to serogroups 12 and 3. III J Food Microbiol 1991: 14: 297304

23. Brosch R. Buchrieser C. Rocourt J. Subtyping of Listeria monocloyenciserovar 4 b by use of low-frequency-cleavage restriction endonucleases and pulsed-field gel electrophoresis. Res Microbiol 1991: 142:667 675 .

24. Bramley AJ. Dodd FH. Reviews on the progress of dairy science: mastitis control -progress and prospects. $J$ Dairy Res 1984: $51: 481$ : 512 .

25. Schalm OW, Carroll EJ. Jain NC (eds). Bovine mastitis. Philadelphia. Lea and Febiger. 1971: 1-22.

26. Griffin TK. Dodd FH. Neave FK. Westgarth DR. Kingwill RG. Wilson CD. A method of diagnosing intramammary infection in dairy cows for large experiments. $J$ Dairy Res 1977: $44: 2545$.
27. Johnson JL, Doyle MP, Cassens RG, Schoeni JL. Fate of Listeria monocytogenes in tissues of experimentally infected cattle and in hard salami. Appl Environ Microbiol 1988; 54 : 497-501.

28. Gaillard JL. Berche P, Mounier J, Richard S. Sansonetti P. Penetration of Listeria monocytogenes into the host: a crucial step of the infectious process. Ann Microbiol (Institut Pasteur) 1987; 138: 259-264.

29. Miettinen A. Husu J, Tuomi J. Serum antibody response to Listeria monocytogenes, listerial excretion, and clinical characteristics in experimentally infected goats. $J$ Clin Microbiol 1990; 28 : 340-343.

30. Audurier A. Pardon P, Marly J. Lantier F, Loulergue J. Mesure de la virulence chez la souris de différentes bactéries appartenant au genre Listeria. Ann Immunol (Institut Pasteur) 1981; 132D: 191-200.

31. Bracegirdle P. West AA, Lever MS, Fitzgeorge RB, Baskerville A. A comparison of aerosol and intragastric routes of infection with Listeria spp. Epidemiol Infect 1994; 112: 69-79.

32. Drevets DA, Canono BP, Leenen PJM, Campbell PA. Gentamicin kills intracellular Listeria monocytogenes. Infect Immun 1994; 62: 2222-2228.

33. International Dairy Federation. Teat tissue reactions to machine milking and new infection risk. Bulletin of the International Dairy Federation 1994: No. 297/1994.

34. International Dairy Federation. Bovine mastitis. Definition and guidelines for diagnosis. Bulletin No. 211, 1987.

35. De Chastellier C, Berche P. Fate of Listeria monocytogenes in murine macrophages: evidence for simultaneous killing and survival of intracellular bacteria. Infect Immun 1994 62: 543-553.

36. Bunning VK. Donnelly CW, Peeler JT et al. Thermal inactivation of Listeria monocytogenes within bovine milk phagocytes. Appl Environ Microbiol 1988; 54: 364-370. 